\title{
Microstructure influence on creep properties of heat-resistant austenitic alloys with high aluminum content
}

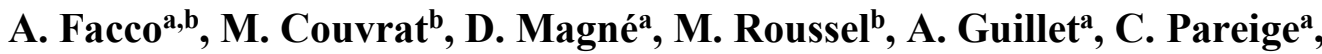

a : Normandie Univ, UNIROUEN, INSA Rouen, CNRS, Groupe de Physique des Matériaux, 76000 Rouen, France.

b : Manoir Industries, 12 rue des Ardennes, 27108 Val de Reuil.

\begin{abstract}
:
This work focusses on the link between microstructure and creep properties for heat-resistant austenitic alloys with high aluminum content (3-5 wt. \%). An emphasis was put on the coupling of thermodynamic simulations, microstructural characterizations by scanning electron microscopy and transmission electron microscopy, and creep testing. The phase predictions performed by the calculation of phase diagrams method are in good agreement with the observed microstructure after creep at $1000^{\circ} \mathrm{C}$ and $1050^{\circ} \mathrm{C}$. Correlation between creep properties and microstructure characterizations at $1000^{\circ} \mathrm{C}$ and $1050^{\circ} \mathrm{C}$ revealed that $\mathrm{NiAl}$ and $\alpha^{\prime}$ (chromium-rich base centered cubic phase) phases are deleterious for the creep properties at service temperature. Several high Al-content alloys are selected in order to replace the chromia-forming alloys standardly used in cracking furnaces.
\end{abstract}

Keywords: heat-resistant; alumina-forming austenitic alloy (AFA); precipitation; creep behavior; alloy design; phases diagram.

\section{Introduction}

Heat resistant austenitic stainless alloys are used in centrifugally cast tubes for cracking furnaces because of their excellent creep and oxidation resistances. A minimum temperature of $850^{\circ} \mathrm{C}$ is needed for the cracking reaction to take place. This temperature is reached by heating the tubes between $950^{\circ} \mathrm{C}$ and $1100^{\circ} \mathrm{C}$ (metal temperature). An unwanted sidereaction of coking happens at the inner surface of the tube during service, it leads to a decrease in heat transfer (as well as an increase in the tube pressure). The tubes then have to be heated at even higher temperatures, typically up to $1100^{\circ} \mathrm{C}-1150^{\circ} \mathrm{C}$ which corresponds to a temperature limit for the material. Moreover, when coking becomes critical, decoking process must be performed. Increase in temperature and decoking process both reduce the tube service life and are very costly.

Nowadays, industrials seek to develop new alloys with high $\mathrm{Al}$ content to improve environmental resistance, especially the coking resistance, by formation of a continuous alumina scale at the inner surface of the furnace tubes. This oxide is more stable than the $\mathrm{Cr}$ oxide at high temperature [1-8]. Nevertheless, Al is known to decrease the creep strength $[6,9,10]$. The understanding of the influence of $\mathrm{Al}$ addition on the microstructure and therefore on the creep properties is essential to find a middle ground between good oxidation properties and good creep resistance.

The influence of $\mathrm{Al}$ on the microstructure and the creep properties of austenitic alloys was widely studied in the temperature range of $550-900^{\circ} \mathrm{C}$. Fe-Ni-Cr-Al alloys (FCNA) with high Al level, between 4 and 5 wt. \%, are used as structural materials combining good mechanical properties and good oxidation resistance thanks to the precipitation of $\mathrm{NiAl}$ phase at $550-650^{\circ} \mathrm{C}[11,12]$. Alumina forming austenitic stainless steels (AFA) with Al-content between 2.5 and $4 \mathrm{wt}$. \% are used for structural purpose in fossil energy conversion and combustion system applications which require good creep and oxidation properties between 650 and $900^{\circ} \mathrm{C}$. Main hardening precipitates in these alloys are MC (M stands for metal like $\mathrm{Nb}$ and $\mathrm{Ti}$ ) carbides and intermetallic compounds such as $\mathrm{NiAl}, \mathrm{Fe}_{2}(\mathrm{Mo}, \mathrm{Nb})$ Laves and $\mathrm{Ni}_{3} \mathrm{Al}$ phases [13-19]. Addition of high $\mathrm{Al}$ level can destabilize the single-phase austenitic matrix by promoting the formation of the weak body-centered cubic $\alpha$-Fe phase resulting in a drop of creep properties $[6,20]$.

For higher temperature applications $\left(>950^{\circ} \mathrm{C}\right)$, nickel base superalloys and austenitic alloys with high Al level were developed. Asteman et al. [8] investigated Ni-base alloys with 4 wt. \% Al (commercial Centralloy ${ }^{\circledR}$ HT-R (Ni25Cr4Al)) and 10 wt. \% $\mathrm{Al}(\mathrm{Ni} 25 \mathrm{Cr} 10 \mathrm{Al})$ for high temperatures applications $\left(600-1200^{\circ} \mathrm{C}\right)$. In Ni25Cr4Al alloy, secondary carbides and $\gamma^{\prime}\left(\mathrm{Ni}_{3} \mathrm{Al}\right)$ precipitation 
allow to obtain sufficient creep properties at high temperature. However, the $\gamma^{\prime}$ particles are not stable at temperature above $1000^{\circ} \mathrm{C}$ which is too low for the applications of our interest [8,21]. The authors [8] showed that the increase in $\mathrm{Al}$ content from 4 wt. \% to 10 wt. $\%$ decreased the oxidation resistance because of the formation of a multiphase cast microstructure. Nevertheless, they did not investigate the influence of this multiphase structure on the creep properties. The heat resistant austenitic alloy Manaurite ${ }^{\circledR}$ XTM without Al allows to reach high temperature while keeping sufficient creep properties [22]. The aim is to design an alloy with $\mathrm{Al}$, equivalent or more resistant in creep, i.e. with lower creep rate, no excessive elongation during service and longer creep service life than the Manaurite ${ }^{\circledR}$ XTM widely used in cracking furnaces.

The challenge is to propose alloys with Al-content higher than $3.5 \mathrm{wt} \%$ in order to increase the environmental resistance while keeping good creep properties. At cracking service temperature (950$1100^{\circ} \mathrm{C}$ ), the creep resistance of these austenitic alloys is mainly guaranteed by the control of secondary precipitation of $\mathrm{MC}$ ( $\mathrm{M}$ stands for metal which is mainly $\mathrm{Nb}$ and $\mathrm{Ti}$ ), and $\mathrm{M}_{23} \mathrm{C}_{6}$ ( $\mathrm{M}$ is mainly $\mathrm{Cr}$ ) carbides. $\mathrm{M}_{23} \mathrm{C}_{6}$ carbides are precipitated owing to transformation of the primary carbides $\mathrm{M}_{7} \mathrm{C}_{3}$ ( $\mathrm{M}$ is mainly $\mathrm{Cr}$ ) formed during solidification [23-28]. However, the influence of high $\mathrm{Al}$ level ( $>3.5 \mathrm{wt} . \%)$ on the microstructure and the creep properties of such alloys is not investigated yet.

This paper focusses on advanced Manaurite ${ }^{\circledR}$ XA14 alloys [29], i.e. on Fe-Ni-Cr-Al alloys of high Ni content (45-55 wt. \%) with alloying addition levels of 25-32 wt. $\% \mathrm{Cr}, 3-5$ wt. \% $\mathrm{Al}$ and 0.45 wt. \% C. The aim is to study the influence of $\mathrm{Al}$ additions on the microstructure and creep properties. Creep tests were performed, and microstructures were characterized after creep in order to make the link between the observed microstructures and the creep resistance. This work relies on the coupling of the CALPHAD (CALculation of PHAse Diagrams) method to forecast the aged microstructure especially the phase stability domains appearing at high temperature (intermetallic phases, hardening precipitates), creep tests and experimental characterization of as cast and ageing microstructures using SEM (Scanning Electron Microscopy) (imaging, EBSD (Electron Backscattered Diffraction) and EDS (Electron Dispersive Spectroscopy)), TEM (Transmission Electron Microscopy) (conventional TEM, STEM (Scanning Transmission Electron Microscopy) and STEM-EDS) and XRD (X-Ray Diffraction).

\section{Materials and methods}

\subsection{Materials}

The tubes were produced by centrifugal casting. The average chemical compositions in weight percent of the FeNiCrAl alloys are provided in Table 1. The C content is measured by a combustion infrared detection technique (LECO) and the others element by SEMEDS. Mn-content was not measured (NM) because of its low concentration $(<0.1 \mathrm{wt}$. \%). Al-content decreases from alloy 4 to alloy 1: alloy 4 (4.8 wt. \%) - alloy 3 (4.5 wt. \%) - alloy 2 (4.1 wt. \%) - alloy 1 (3.5 wt. \%). Except $\mathrm{Al}$ content, the chemical compositions of alloys 1 and 2 are close. These two alloys present the lowest $\mathrm{Cr}$ concentration ( $\sim 26 \mathrm{wt} . \%)$. Cr content is higher in alloy 3 and alloy 4 (30-32 wt. \%). These two alloys have similar composition except in Al. Alloy 5 contains high levels of $\mathrm{Al}(4.7$ wt. \%) and $\mathrm{Ni}(55 \mathrm{wt} . \%)$ and 26 wt. \% of Cr. The commercial Manaurite ${ }^{\circledR}$ XTM which is without $\mathrm{Al}$ represents the reference alloy.

Table 1: Average chemical composition of the FeNiCrAl alloys (wt. \%).

\begin{tabular}{cccccccccc}
\hline Element (wt. \%) & $\begin{array}{c}\text { C- } \\
\text { LECO }\end{array}$ & Mn & Si & Ni & Cr & Nb & Al & Ti & Fe \\
\hline Alloy 1 & 0.43 & NM & 0.3 & 47.1 & 25.6 & 0.9 & 3.5 & 0.1 & Bal. \\
\hline Alloy 2 & 0.44 & NM & 0.3 & 46.8 & 26.0 & 0.8 & 4.1 & 0.1 \\
\hline Alloy 3 & 0.43 & NM & 0.4 & 44.7 & 30.8 & 0.9 & 4.5 & 0.1 \\
\hline Alloy 4 & 0.46 & NM & 0.3 & 44.8 & 31.8 & 0.7 & 4.8 & 0.1 \\
\hline Alloy 5 & 0.43 & NM & 0.3 & 55.0 & 25.9 & 0.8 & 4.7 & 0.3 \\
\hline XTM & 0.45 & 1.4 & 1.4 & 44.3 & 37.0 & 0.6 & 0 & 0.1 \\
\hline
\end{tabular}




\subsection{Creep testing}

Short creep tests at constant load were performed. Cylindrical creep specimens were machined in the center of the tube, perpendicular to the direction of dendrites and to the columnar grains as shown Figure 1 which presents schematic of the creep specimen sampling in the columnar zone of the centrifugal cast tube.

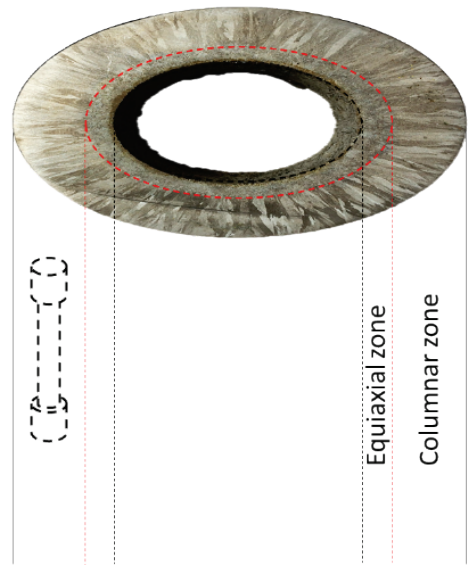

Figure 1: schematic of the creep specimen sampling in the columnar zone.

Creep specimens with a diameter of $4 \mathrm{~mm}$ and a gauge length of $32 \mathrm{~mm}$ were used for creep tests. The strain was measured on the line with a laser device. The creep tests were performed at $1000^{\circ} \mathrm{C}$ and $1050^{\circ} \mathrm{C}$ under constant loads with initial stresses between $17 \mathrm{MPa}$ and $31 \mathrm{MPa}$. The creep duration ranged between $33 \mathrm{~h}$ and $1214 \mathrm{~h}$ depending on the creep resistance and the creep conditions (temperature and creep load). The different alloys were tested in the as-cast state, i.e. without any additional thermal treatments before creep testing. After fracture, the creep specimens were water-quenched from the creep test temperature.

\subsection{Characterizations techniques}

XRD measurements were performed on as cast samples with a Brüker D8 diffractometer with $\mathrm{Co}-\mathrm{K} \alpha$ radiation $(\lambda=1.789 \AA)$ at $35 \mathrm{kV}$ from $25^{\circ}$ to $100^{\circ}$. Samples were polished up to $5 \mu \mathrm{m}$.

Standard sample preparation has been performed for the SEM characterization. Longitudinal cross sections were cut into the crept specimens in order to observe the microstructure along the creep direction. The SEM samples were mechanically polished with $\mathrm{SiC}$ grinding papers up to $5 \mu \mathrm{m}$ and with diamond suspensions up to $1 \mu \mathrm{m}$. For EBSD samples, finer polishing with diamond suspension of $0.25 \mu \mathrm{m}$ and colloidal silica suspension $(0.04 \mu \mathrm{m})$ was performed. SEM characterizations were carried out with a JEOL $7900 \mathrm{~F}$ operating at $15 \mathrm{kV}$.
EBSD measurements were done with a Hikari EBSD camera.

TEM samples were prepared from $3 \mathrm{~mm}$ disk. They were mechanically polished by $\mathrm{SiC}$ grinding papers up to $5 \mu \mathrm{m}$ and a thickness of $100 \mu \mathrm{m}$ then an electrolytical etching by $10 \%$ perchloric acid and $90 \%$ acetic acid solution at $14^{\circ} \mathrm{C}$ and $20 \mathrm{~V}$ was realized with a twin jet electropolisher (Tenupol 5 from Struers). Afterwards, a final polishing was performed by ion milling (PIPS II from Gatan operating at $3 \mathrm{keV}+3^{\circ}$ during $5 \mathrm{~min}$ ). TEM characterizations were carried out with a probe corrected JEOL ARM-200F at $200 \mathrm{kV}$.

\subsection{Thermodynamic simulations}

Computational thermodynamic calculations were done with the commercial Thermo-Calc (C) software. Because of the high level of $\mathrm{Ni}$ in the studied alloys, between 44 and 55 wt. \%, the more relevant database is the Nickel base (TCNI8 [30]). The Nickel database allows prediction of the phases observed in these alumina-forming austenitic alloys, particularly, $\mathrm{Ni}_{3} \mathrm{Al}$ and $\mathrm{NiAl}$ phases which are not predicted by the Iron database (TCFE8 [31]).

\section{Experimental results}

\subsection{Microstructural characterization}

\subsubsection{As-cast microstructure}

The centrifugation process and the fast cooling rate promote the formation of a large columnar zone as shown in the crystallographic orientation maps of alloy 2 (Figure 2). Such large grains are beneficial for creep properties at high temperature for this kind of alloy. The average grain size in the transversal cross-section is higher than $400 \mu \mathrm{m}$ for the five alloys.

The dendritic structure of these heat-resistant alloys is composed of an austenitic matrix with $\mathrm{M}_{7} \mathrm{C}_{3} \mathrm{Cr}$-rich carbides and $(\mathrm{Nb}$; Ti)-rich carbides (hereafter named MC) observed at the grain boundaries and interdendritic spaces as shown in Figure 3a). The presence of both $\mathrm{Ti}$ and $\mathrm{Nb}$ in $\mathrm{MC}$ carbides was confirmed by SEM-EDS measurements (Figure 3b)).

Figure 4 presents XRD spectra obtained in alloys 1 to 5 . M7C3 and MC are observed after solidification in the five alloys. In these different alloys, Ni3 Al phase also appears during the solidification. $\mathrm{M} 7 \mathrm{C} 3$ and $\mathrm{MC}$ surface 
fractions in the as cast state for these five alloys are very similar as reported in Table 2. These surface fractions were obtained by image analysis from several SEM electron back-scattered images.

a)
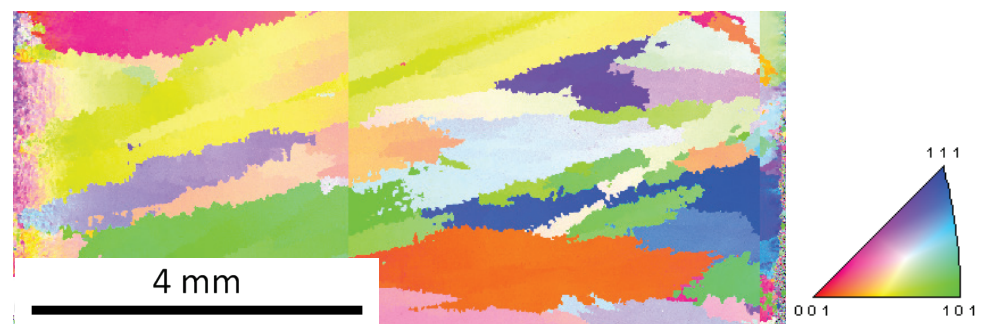

b)
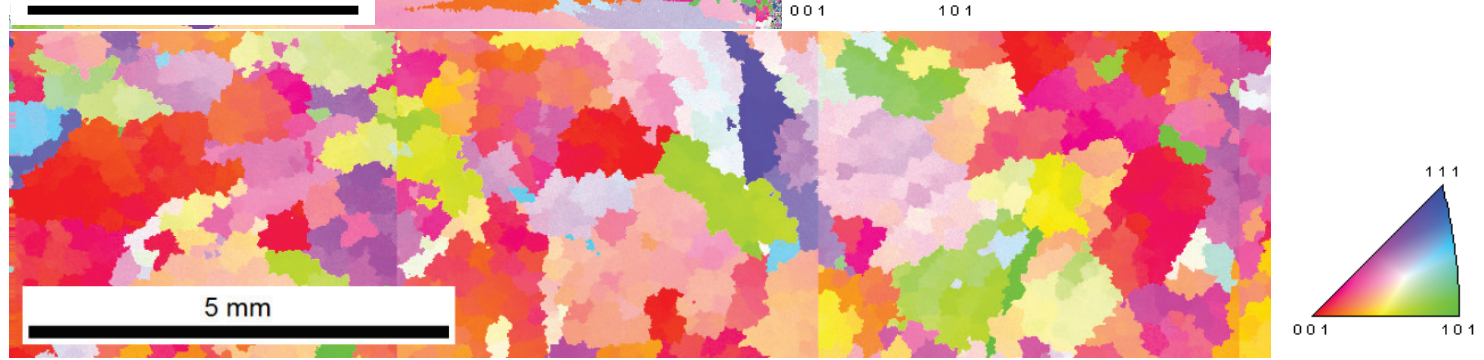

Figure 2: SEM-EBSD crystallographic orientation maps of a) the transversal cross-section and b) the longitudinal cross-section of alloy 2. (color should be used)

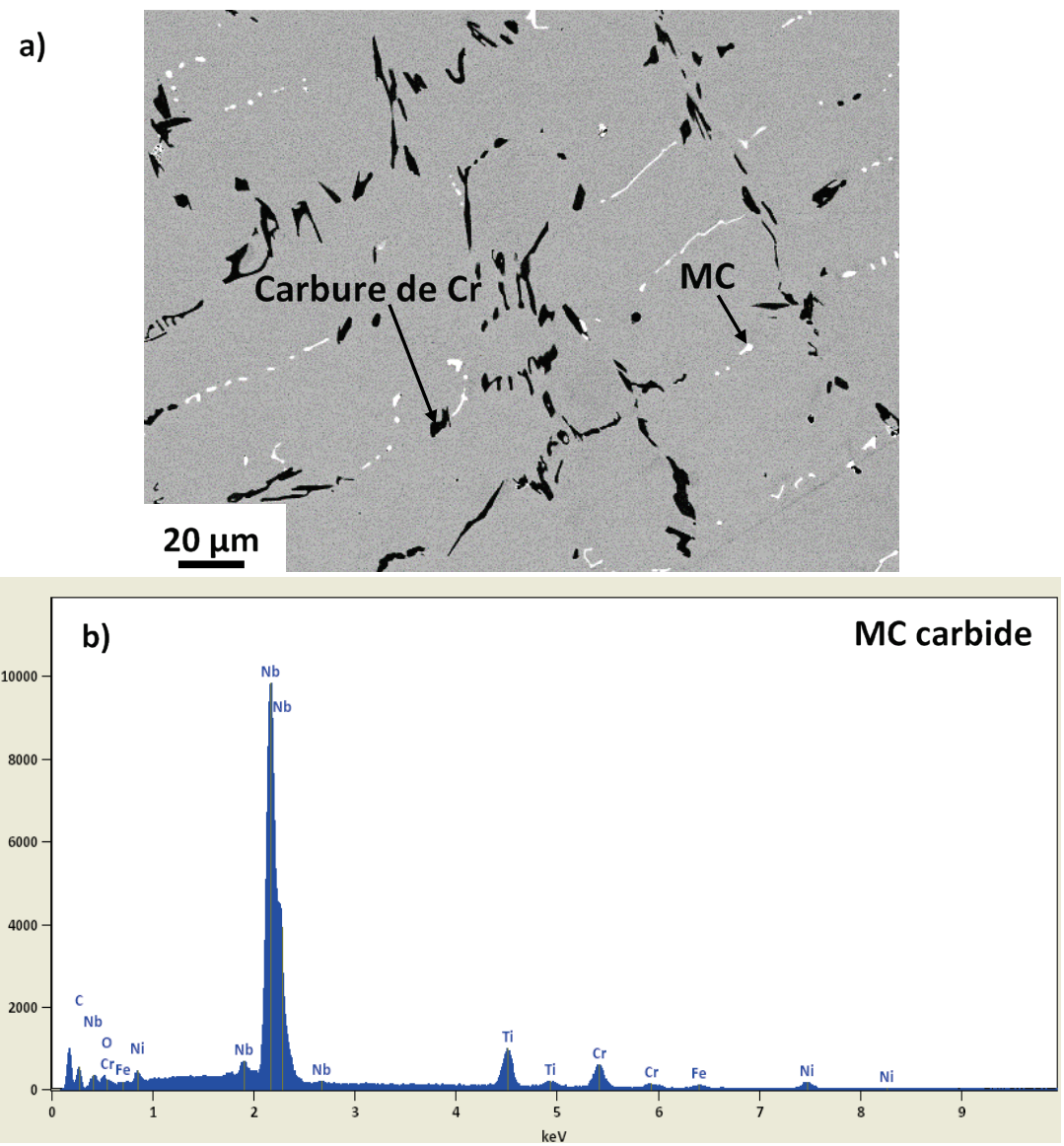

Figure 3: a) SEM back-scattered electron image of the as-cast alloy 2, MC carbides are in white, $\mathrm{M}_{7} \mathrm{C}_{3}$ in dark, and b) EDS spectrum performed in MC carbide. 


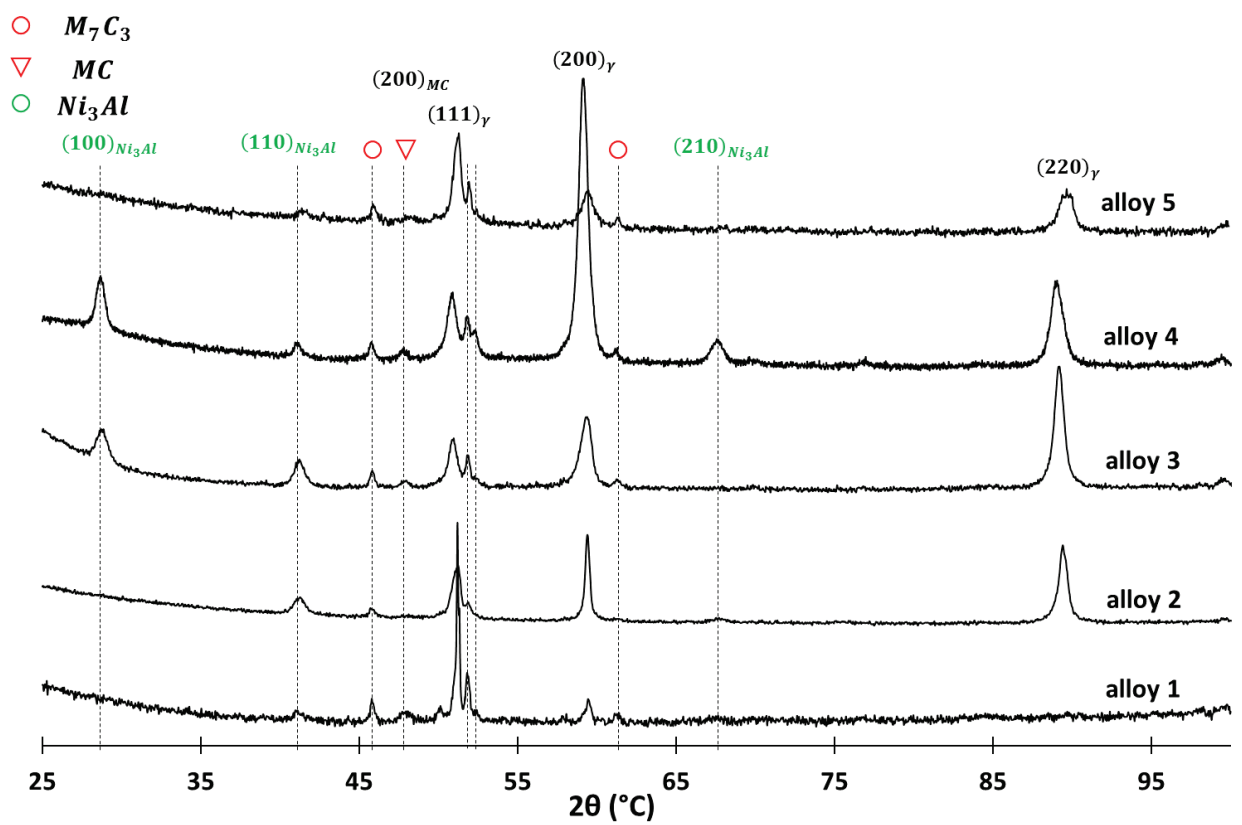

Figure 4: Diffraction spectra of the alloys 1, 2, 3, 4 and 5.

Table 2: Measured carbides surface fractions

\begin{tabular}{ccc}
\hline & $\mathbf{f}_{\mathbf{M}_{7} \mathbf{C}_{3}}$ & $\mathbf{f}_{\mathrm{MC}}^{\mathbf{s}}$ \\
\hline Alloy 1 & $4.4 \pm 0.2$ & $0.6 \pm 0.1$ \\
\hline Alloy 2 & $4.8 \pm 0.4$ & $0.7 \pm 0.1$ \\
\hline Alloy 3 & $5.0 \pm 0.5$ & $0.6 \pm 0.1$ \\
\hline Alloy 4 & $4.9 \pm 0.2$ & $0.7 \pm 0.1$ \\
\hline Alloy 5 & $4.7 \pm 0.5$ & $0.6 \pm 0.1$ \\
\hline
\end{tabular}

\subsubsection{Microstructure after creep at service temperature}

Figure 5 presents the molar fractions of phases as a function of temperature for alloys 1 to 5 . The phase diagrams have been calculated using the CALPHAD method. At service temperature $\left(950-1100^{\circ} \mathrm{C}\right)$, the classical phases expected in refractory steels without $\mathrm{Al}$ addition, are the austenitic matrix, $\mathrm{M}_{23} \mathrm{C}_{6} \mathrm{Cr}$-rich carbides and the $\mathrm{MC}$ type carbides rich in carbide former elements such as $\mathrm{Nb}$ and Ti. According to the thermodynamic simulations, because of the high levels of $\mathrm{Al}$ and $\mathrm{Cr}, \mathrm{B} 2 \mathrm{NiAl}$ and $\mathrm{Cr}$-rich BCC (chromium-rich base centered cubic) $\alpha^{\prime}$ (base centered cubic chromiumrich) phases can precipitate. NiAl and $\alpha^{\prime}$ phases are not expected at service temperature in alloys 1,2 and 5 . Indeed, $\mathrm{NiAl}$ and $\alpha^{\prime}$ are predicted, up to $950^{\circ} \mathrm{C}$ and $896^{\circ} \mathrm{C}$ respectively for alloy 2 and up to $954^{\circ} \mathrm{C}$ and $921^{\circ} \mathrm{C}$ respectively for alloy 5 . In alloy $1, \alpha$ ' is stable up to $887^{\circ} \mathrm{C}$ and no NiAl phase is expected whatever the temperature. However, due to the addition of high contents of $\mathrm{Al}$ and $\mathrm{Cr}$, and low content of $\mathrm{Ni}$ in alloys 3 and 4, NiAl and $\alpha$ ' phases appear and become stable at service temperature in these alloys (Figure 5). The $\mathrm{Ni}_{3} \mathrm{Al}$ phase is not stable at service temperature even for the alloy 5 containing high levels of $\mathrm{Al}$ and $\mathrm{Ni}$.

Backscattered electron images of alloys after annealing at $1050^{\circ} \mathrm{C}$ during $100 \mathrm{~h}$ are shown in Figure 6. In good agreement with the phase diagrams of Figure 5, only $\mathrm{MC}$ (bright contrast) and $\mathrm{M}_{23} \mathrm{C}_{6}$ carbides (darkest phase) are observed in alloys 1, 2 and 5 (Figure 6a, Figure $6 \mathrm{~b}$ and Figure $6 \mathrm{e}$ respectively). Two types of $\mathrm{M}_{23} \mathrm{C}_{6}$ carbides are present: coarse $\mathrm{M}_{23} \mathrm{C}_{6}$ carbides originating from the transformation of the primary $\mathrm{M}_{7} \mathrm{C}_{3}$ carbides and finely dispersed secondary carbides $\mathrm{M}_{23} \mathrm{C}_{6}$ resulting from the release of $\mathrm{C}$ in the matrix during the transformation of $\mathrm{M}_{7} \mathrm{C}_{3}$ into $\mathrm{M}_{23} \mathrm{C}_{6}$ [26,28]. In alloys 3 and 4 (Figure $6 \mathrm{c}$ and Figure $6 \mathrm{~d}$ respectively), an additional phase in light grey contrast is observed. This 
phase appears under two different types: under the form of plate shape precipitates dispersed in the $\gamma$ matrix (further called type I) and type II which forms at the interface between $\mathrm{Cr}$ carbides and the austenitic matrix. The phase has been identified thanks to TEM investigations as NiAl phase. Figure 7 presents type I $\mathrm{NiAl}$ precipitate and the Figure 8 a TEM image and the corresponding selected area electron diffraction pattern (SAED) of the NiAl phase in [012] zone axis in alloy 4 crept at $1050^{\circ} \mathrm{C}$.

The $\alpha$ ' phase was also identified by TEM in alloys 3 and 4 at $1050^{\circ} \mathrm{C}$. The phase forms nanoscale precipitates mainly observed at matrix/ $\mathrm{NiAl}$ interfaces and in the NiAl phase as shown on the TEM image of Figure 7 and
Figure 8 . These nanoscale precipitates are invisible on SEM images. According to the SAED patterns performed in $\alpha^{\prime}$ and NiAl phases, the crystallographic relationship is cube-cube. The lattice parameter of the NiAl phase was determined considering the lattice substructure diffraction spots of the SAED pattern Figure $8 \mathrm{~b}$ ) and is $a_{N i A l}=2.83 \pm 0.07 \AA$ and the lattice parameter of the $\alpha^{\prime}$ phase was determined using the SAED pattern Figure 8c) and is $a_{\alpha^{\prime}}=2.89 \pm 0.09 \AA$. The obtained value are similar to those observed in the literature : $a_{N i A l} \cong 2.88-2.89 \AA[10,11,18,19]$ and $a_{\alpha^{\prime}} \cong 2.88 \AA \quad[18]$. The cube-cube orientation relationship and the close lattice parameters indicate that these phases are coherent.
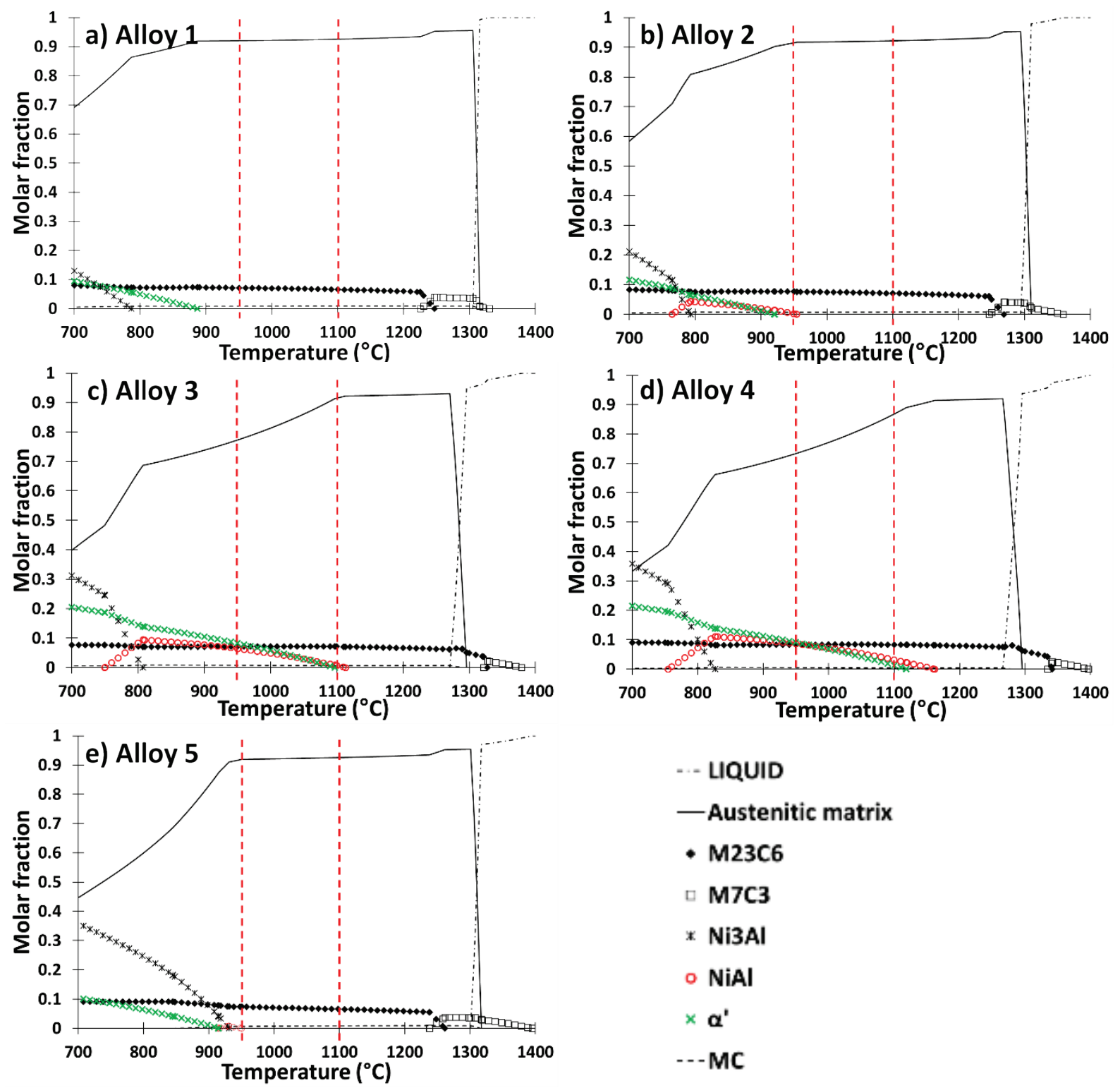

Figure 5: Mole fraction of phase as a function of temperature according to TCNI8 [32]. Red dashed lines define the service temperature range $\left(950^{\circ} \mathrm{C}-1100^{\circ} \mathrm{C}\right)$. 


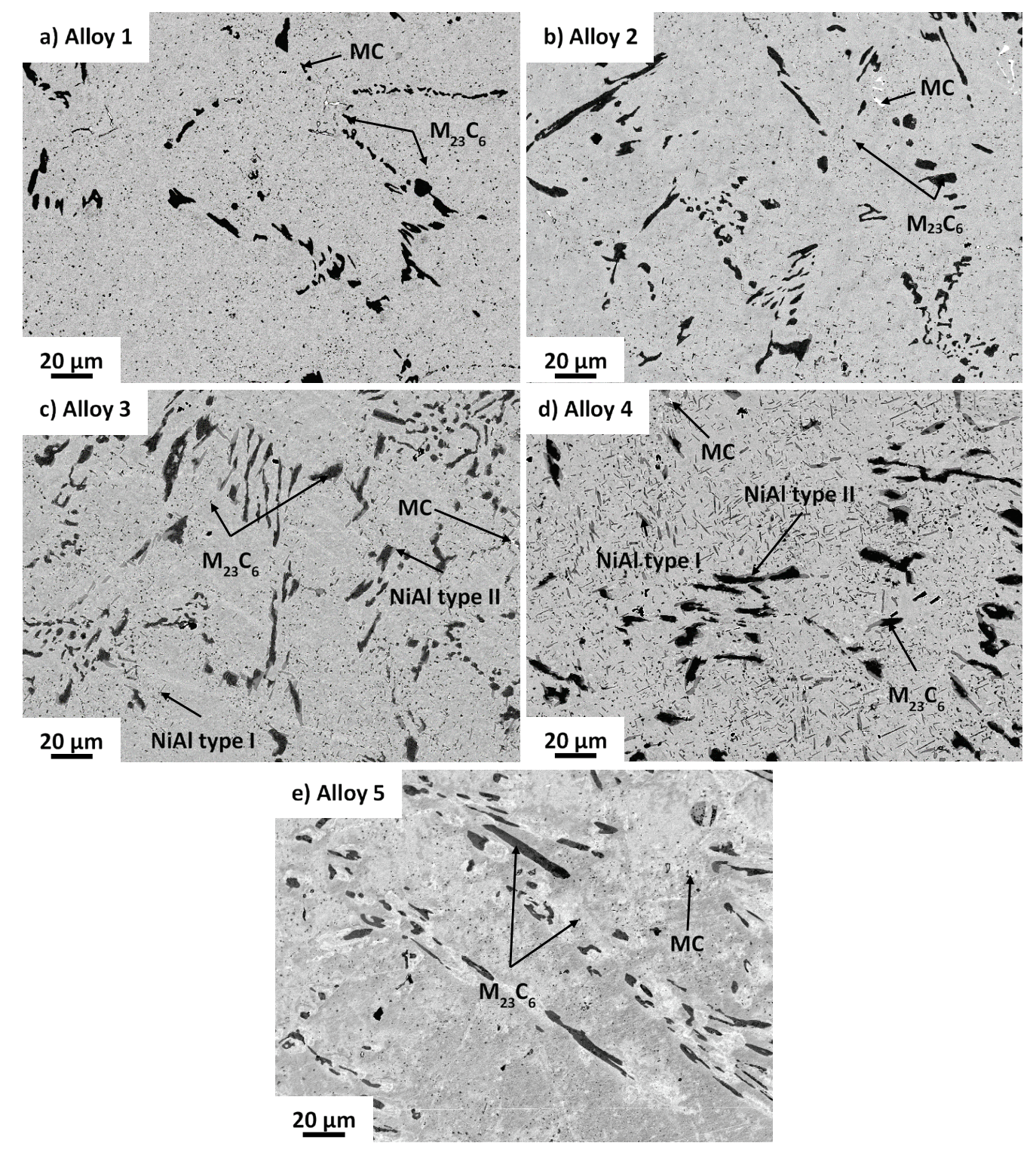

Figure 6: Backscattered electron images of alloys 1, 2, 3, 4 and 5 after annealing at $1050^{\circ} \mathrm{C}$ during $100 \mathrm{~h}$.
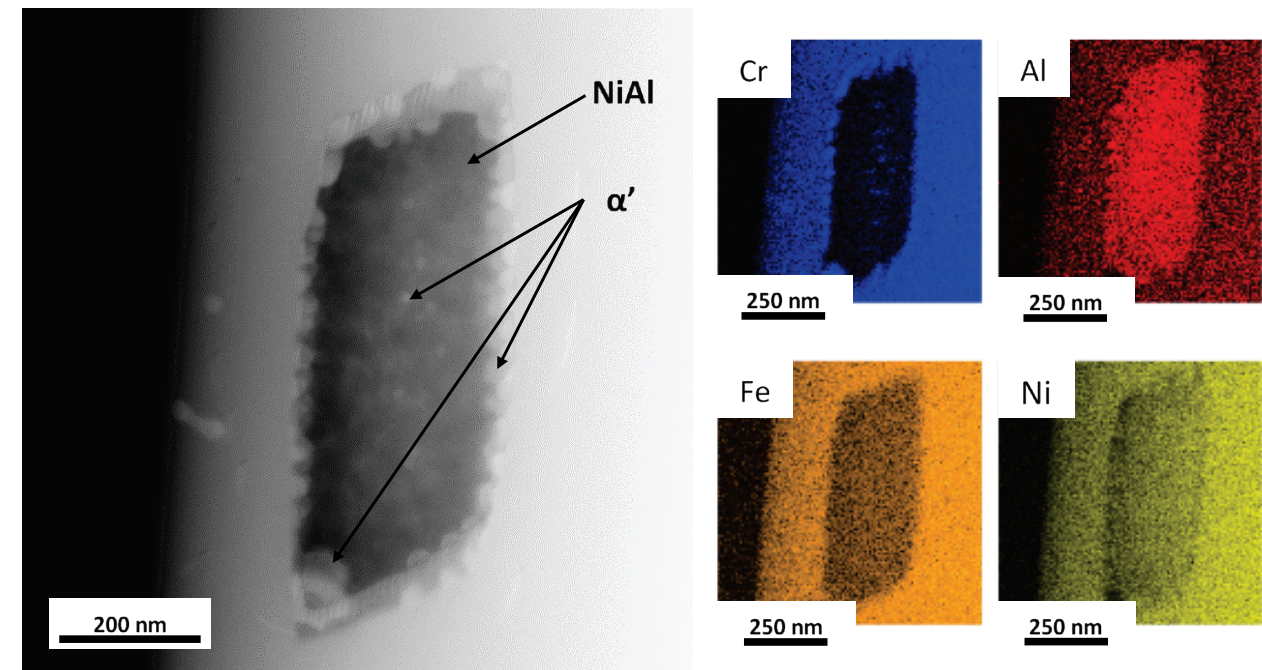

Figure 7: Dark field STEM image of NiAl plate and the corresponding TEM-EDS element maps performed in the alloy 4 after creep at $1050^{\circ} \mathrm{C}$. (color should be used) 


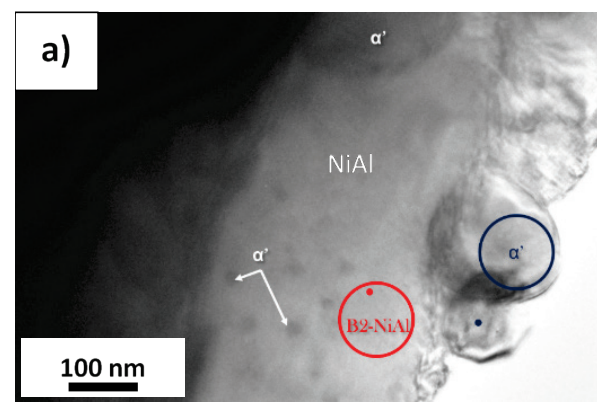

b)

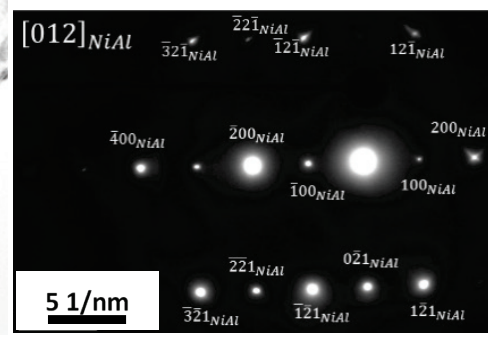

c)

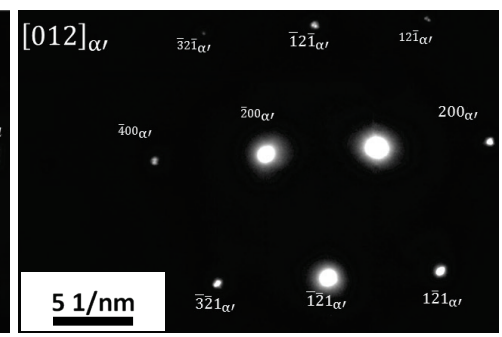

Figure 8: a) TEM image, b) the corresponding SAED performed in the NiAl phase and c) the corresponding SAED performed in the $\alpha^{\prime}$ phase in the alloy 4 after creep at $1050^{\circ} \mathrm{C}$.

The different spatial scales involved, the heterogeneous distribution of the phases and the low contrast between phases make difficult phase fraction measurements. For these reasons only phase compositions have been measured and compared to compositions predicted by the Nickel database (TCNI8) of the CALPHAD method at $1050^{\circ} \mathrm{C}$. Comparison is performed in Table 3 for NiAl and $\alpha^{\prime}$ phases after creep at $1050^{\circ} \mathrm{C}$ and show a very good agreement. All these results validate the use of the thermodynamic simulations via TCNI8 for these alloys. It is thus possible to use the thermodynamic data base to estimate mole fractions of the phases in the alloys. Mole fractions of NiAl, $\alpha^{\prime}, \mathrm{MC}$ and M23C6 for the five alloys are given in Table 4 at $1000^{\circ} \mathrm{C}$ and $1050^{\circ} \mathrm{C}$. To summarize: alloys 1, 2 and 5 do not contain any NiAl and $\alpha^{\prime}$ phases, only secondary MC and M23C6 develop. $\mathrm{NiAl}$ and $\alpha^{\prime}$ phases are observed in alloys 3 and 4 with the highest molar fractions in alloy 4 for both phases.

Table 3: Chemical compositions of $\mathrm{NiAl}$ and $\alpha^{\prime}$ phases after creep at $1050^{\circ} \mathrm{C}$ in alloy 4 as measured by TEM-EDS. Also provided TCNI8 predicted compositions.

\begin{tabular}{ccccc}
\hline & \multicolumn{3}{c}{ NiAl } & \multicolumn{2}{c}{} \\
\hline & TEM-EDS (wt. \%) & TCNI8 (wt. \%) & TEM-EDS (wt. \%) & TCNI8 (wt. \%) \\
\hline $\mathrm{Ni}$ & 63.7 & 63.7 & 9.4 & 7.0 \\
\hline $\mathrm{Al}$ & 19.8 & 18.3 & 1.4 & 0.6 \\
\hline $\mathrm{Fe}$ & 8.7 & 10.3 & 12.0 & 76.7 \\
\hline $\mathrm{Cr}$ & 7.5 & 7.2 & 77.2 & \\
\hline $\mathrm{Nb}$ & 0.3 & 0.3 & & \\
\hline $\mathrm{Ti}$ & - & 0.1 & & \\
\hline
\end{tabular}

Table 4: TCNI8 predicted NiAl, $\alpha^{\prime}, \mathrm{M}_{23} \mathrm{C}_{6}$ and $\mathrm{MC}$ molar fractions at $1000^{\circ} \mathrm{C}$ and $1050^{\circ} \mathrm{C}$.

\begin{tabular}{|c|c|c|c|c|c|c|c|c|}
\hline \multirow{2}{*}{ Molar fractions } & \multicolumn{2}{|c|}{$\mathbf{f}_{\text {NiAl }}^{\mathrm{TC}}$} & \multicolumn{2}{|c|}{$\mathbf{f}_{\mathbf{\alpha}^{\prime}}^{\mathrm{TC}}$} & \multicolumn{2}{c|}{$\mathbf{f}_{\mathbf{M}_{\mathbf{2}} \mathbf{C}_{\mathbf{6}}}^{\mathrm{TC}}$} & \multicolumn{2}{c|}{$\mathbf{f}_{\mathbf{M C}}^{\mathrm{TC}}$} \\
\hline & $1000^{\circ} \mathrm{C}$ & $1050^{\circ} \mathrm{C}$ & $1000^{\circ} \mathrm{C}$ & $1050^{\circ} \mathrm{C}$ & $1000^{\circ} \mathrm{C}$ & $1050^{\circ} \mathrm{C}$ & $1000^{\circ} \mathrm{C}$ & $1050^{\circ} \mathrm{C}$ \\
\hline Alloy 1 & 0 & 0 & 0 & 0 & 7.0 & 6.8 & 0.9 & 0.9 \\
\hline Alloy 2 & 0 & 0 & 0 & 0 & 7.5 & 7.3 & 0.7 & 0.7 \\
\hline Alloy 3 & 4.9 & 3 & 5.9 & 3 & 7.2 & 7.2 & 0.7 & 0.7 \\
\hline Alloy 4 & 7.2 & 5.4 & 6.8 & 4.2 & 8.4 & 8.4 & 0.5 & 0.5 \\
\hline Alloy 5 & 0 & 0 & 0 & 0 & 6.6 & 6.9 & 0.8 & 0.8 \\
\hline
\end{tabular}

At $1000^{\circ} \mathrm{C}$, higher mole fractions of $\mathrm{NiAl}$ and $\alpha^{\prime}$ are present in alloys 3 and 4 . Other features consisting in duplex structures of $\mathrm{NiAl}$ and $\alpha$ appear at this temperature in these alloys as shown in Figure 9. Creep cavities are observed at $\mathrm{NiAl} /$ carbides interface. It is worth noting that no cavities or micro-cavities are 
observed in as-cast materials. Centrifugation process ensures to obtain materials without any porosity.

Although NiAl phase is not predicted by the CALPHAD method for alloy 2 (Figure 5), SEM characterization of alloy 2 crept at $1000^{\circ} \mathrm{C}$ for $89.8-99.2 \mathrm{~h}$ reveals that this phase is present (Figure 10). As for alloys 3 and 4, creep cavities seem to appear preferentially at the $\mathrm{NiAl} /$ carbides interfaces. In order to check the stability of the NiAl phase in alloy 2 at $1000^{\circ} \mathrm{C}$, annealing treatments at $1000^{\circ} \mathrm{C}$ during $16 \mathrm{~h}$ and $176 \mathrm{~h}$ followed by a water-quench were performed. After $16 \mathrm{~h}$ the NiAl phase is present at the carbides/matrix interfaces (Figure 11a)) but disappears after $176 \mathrm{~h}$ (Figure 11b)). Consequently, as predicted by the thermodynamic simulations, the NiAl phase is not stable at $1000{ }^{\circ} \mathrm{C}$. This confirms the validity of the CALPHAD phase diagrams. This phase which is not present after solidification and after annealing treatment at $1000^{\circ} \mathrm{C}$ during $176 \mathrm{~h}$, appears during short creep test (89.8-99.2 h) at $1000^{\circ} \mathrm{C}$ or during short thermal ageing $(16 \mathrm{~h})$. Appearance and dissolution of this phase during ageing or creep can be explained as follows. As shown by Roussel et al. [28], depletion in $\mathrm{Cr}$ and enrichment in $\mathrm{Ni}$ at the primary Cr-carbide/matrix interface after solidification (Figure 12). The presence of these chemical gradients at the matrix/carbide interface after solidification can act as an additional driving force for the heterogeneous nucleation of the NiAl phase. This agrees with the fact that only type I NiAl particles are observed. Similarly, some type II NiAl particles not predicted by the thermodynamic simulations appear in alloy 5 during creep at $1000^{\circ} \mathrm{C}$.

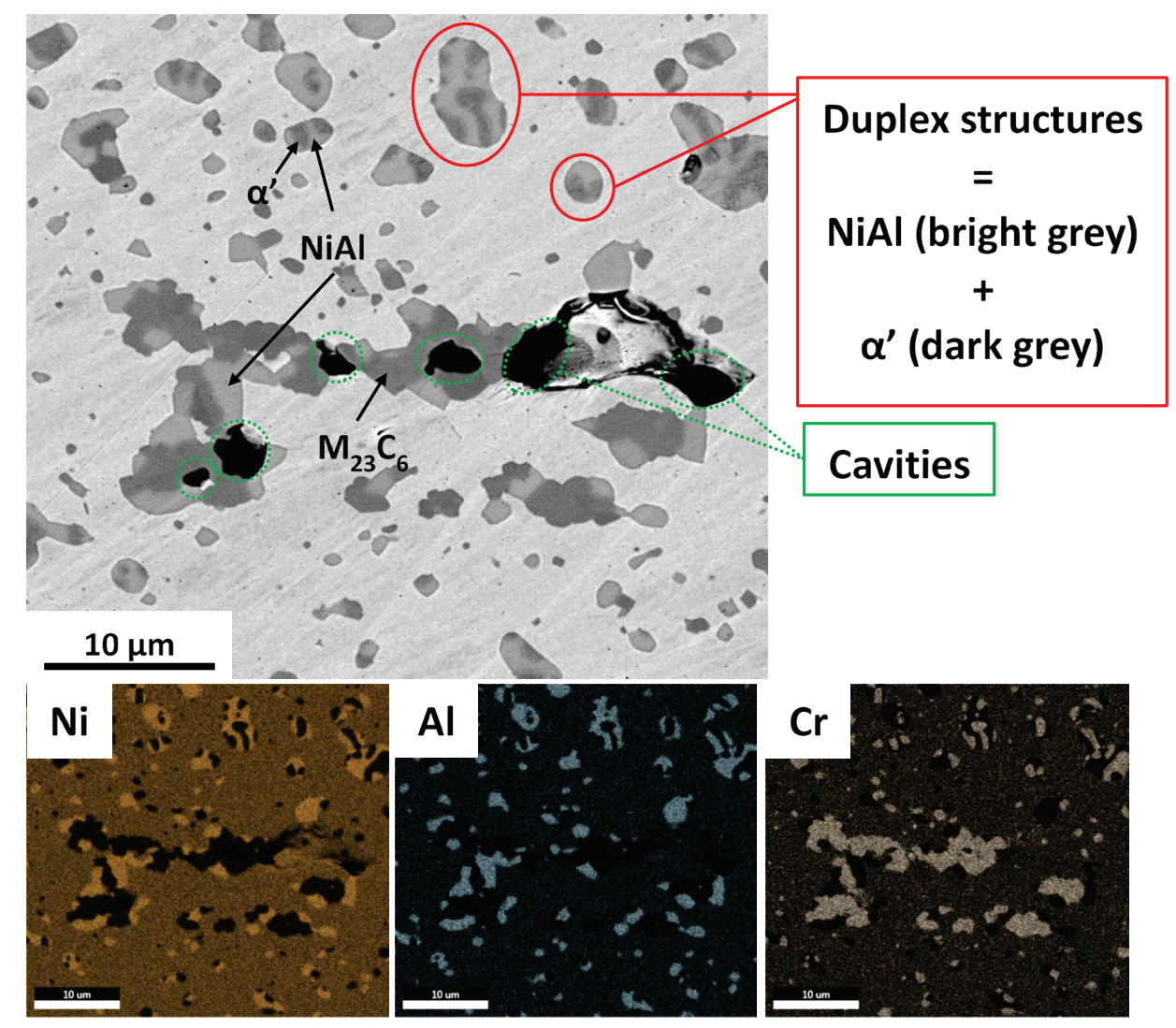

Figure 9: Backscattered electron image of alloy 4 after creep at $1000^{\circ} \mathrm{C} 31 \mathrm{MPa}$ and the corresponding EDS-Ni and EDS-Al maps. $\mathrm{M}_{23} \mathrm{C}_{6}$ and $\alpha^{\prime}$ are in dark grey and $\mathrm{NiAl}$ in bright grey. Are also pointed out creep cavities (green dash lines) and duplex structures (red bold lines). (color should be used) 


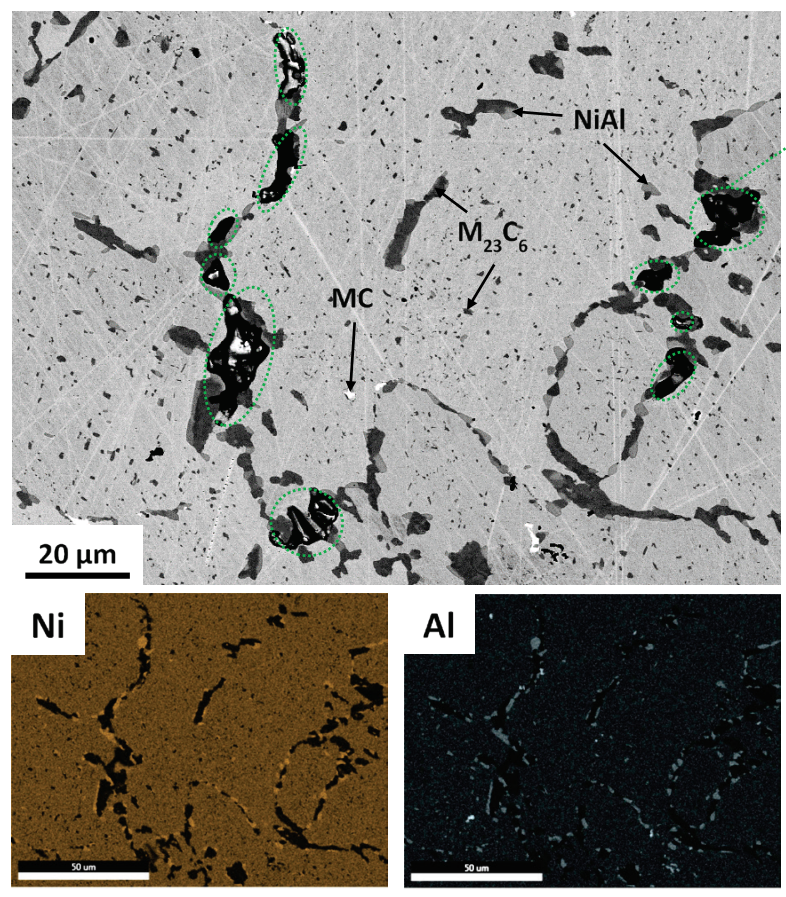

\section{Cavities}

Figure 10: Backscattered electron image of alloy 2 after creep at $1000^{\circ} \mathrm{C} 31 \mathrm{MPa}$ and the corresponding EDS-Ni and EDS-Al maps. $\mathrm{MC}$ carbides are in white, $\mathrm{M}_{23} \mathrm{C}_{6}$ in dark grey and $\mathrm{NiAl}$ in bright grey. Are also pointed out the creep cavities (green dash lines). (color should be used)

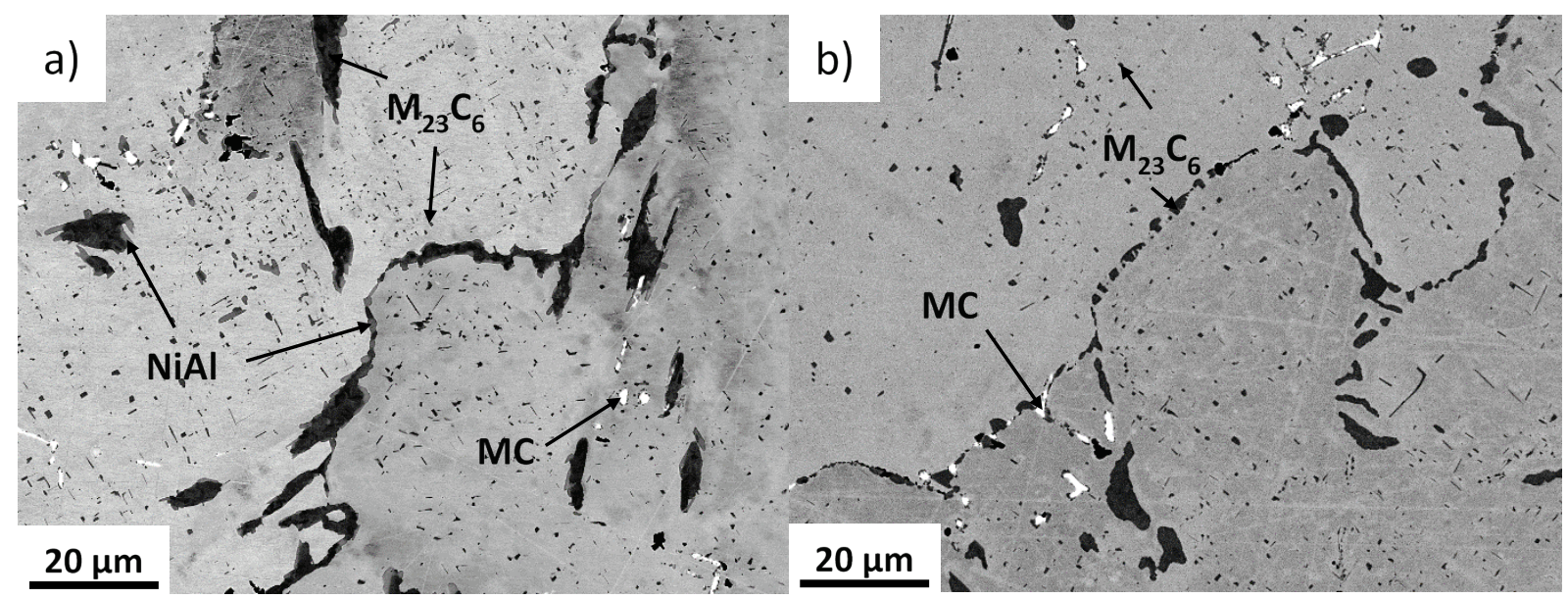

Figure 11: Backscattered electron images of alloy 2 annealed at $1000^{\circ} \mathrm{C}$ a) during $16 \mathrm{~h}$ and b) during $176 \mathrm{~h}$ then waterquenched. $\mathrm{MC}$ carbides are in white, $\mathrm{M}_{23} \mathrm{C}_{6}$ in dark grey and $\mathrm{NiAl}$ in bright grey.

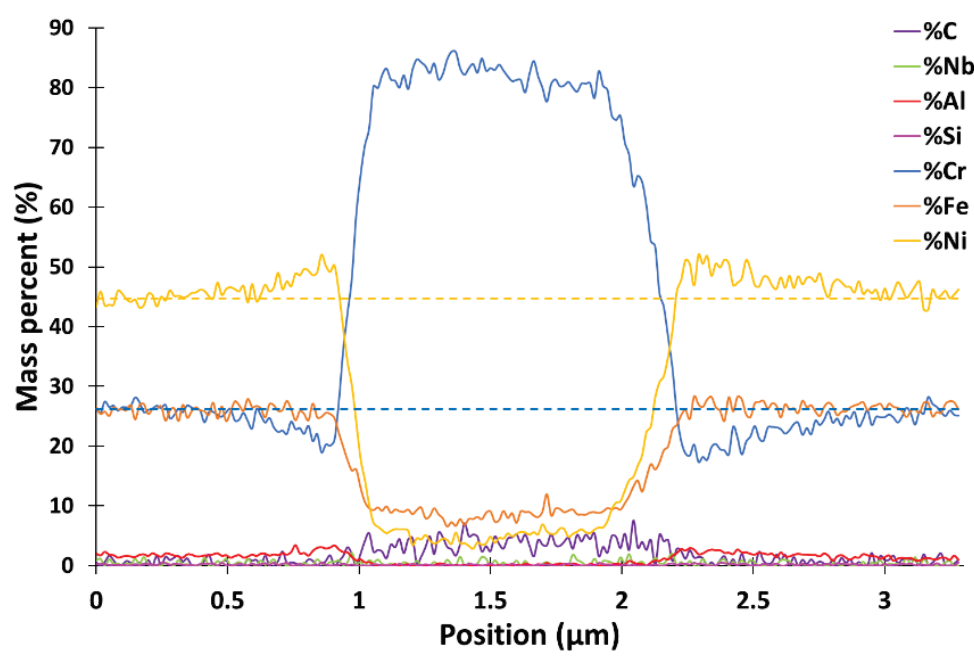

Figure 12: STEM-EDS profile at the $\mathrm{M}_{7} \mathrm{C}_{3} /$ matrix interface. (color should be used) 


\subsection{Creep behavior}

Creep tests were conducted at $1000^{\circ} \mathrm{C}$ and $1050^{\circ} \mathrm{C}$ under stresses from $17 \mathrm{MPa}$ to $31 \mathrm{MPa}$. Figure 13 presents the creep curves of alloys 1 to 5 and the Manaurite XTM ${ }^{\circledR}$ obtained at $1050^{\circ} \mathrm{C}$ under $17 \mathrm{MPa}$.

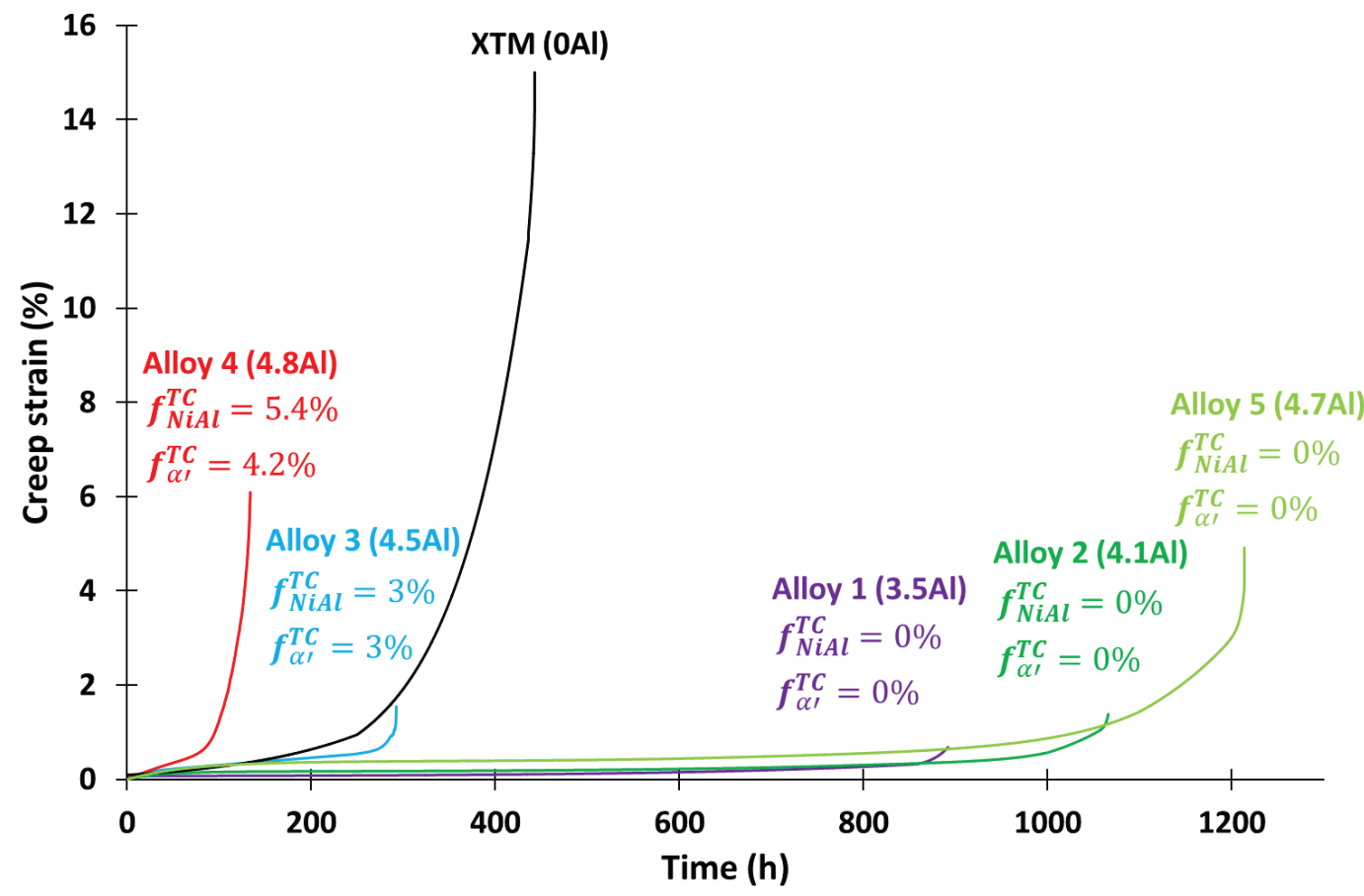

Phases observed in the crept specimen are the same as those observed in the alloys annealed at $1050^{\circ} \mathrm{C}$ during $100 \mathrm{~h}$. In Table 5, rupture time $\mathrm{t}_{\mathrm{r}}(\mathrm{h})$, elongation at break $\mathrm{A}_{\mathrm{r}}(\%)$ and minimum creep rate in secondary stage $\dot{\varepsilon}$ $(\% / h)$ are provided. The NiAl presence in the crept specimen are also indicated by a cross mark in Table 5.

Figure 13: Creep curves at $1050^{\circ} \mathrm{C}$ under $17 \mathrm{MPa}$. Are also reported the predicted mole fractions $\alpha^{\prime}$ and $\mathrm{NiAl}$ and the Al-contents.

Table 5: Elongation at break, creep rupture time and minimum creep rate at $1050^{\circ} \mathrm{C}$ under $17 \mathrm{MPa}$ and $22.2 \mathrm{MPa}$. Also given the NiAl presence (cross mark) in the crept specimen.

\begin{tabular}{|c|c|c|c|c|c|c|c|c|}
\hline \multirow[b]{2}{*}{$\sigma(\mathrm{MPa})$} & \multicolumn{2}{|c|}{$A_{r}(\%)$} & \multicolumn{2}{|c|}{$\mathbf{t}_{\mathbf{r}}(\mathrm{h})$} & \multicolumn{2}{|c|}{$\dot{\varepsilon}\left(\cdot 10^{-3} \% / h\right)$} & \multicolumn{2}{|c|}{$\mathrm{NiAl}$ presence } \\
\hline & 17 & 22.2 & 17 & 22.2 & 17 & 22.2 & 17 & 22.2 \\
\hline XTM & 15.0 & 11.7 & 442.6 & 125.1 & 1.2 & 2.7 & & \\
\hline Alloy 1 & 0.7 & $0.8-1.3$ & 891.6 & 236.4-331.9 & 0.1 & $0.9-2.0$ & & \\
\hline Alloy 2 & 1.4 & $1.5-3.2$ & 1065.7 & $211.8-330.5$ & 0.1 & $1.1-1.5$ & & \\
\hline Alloy 3 & 1.5 & $3.6-5.5$ & 292.3 & $53.0-59.3$ & 1.6 & $5.2-8.5$ & $\mathrm{X}$ & $\mathrm{X}$ \\
\hline Alloy 4 & 6.1 & $3.9-4.3$ & 133.7 & $33.7-35.7$ & 6.0 & $11.7-37.7$ & $\mathrm{X}$ & $X$ \\
\hline Alloy 5 & 4.9 & $4.5-5.9$ & 1213.5 & $165.6-161.3$ & 0.1 & $3.8-4.8$ & & \\
\hline
\end{tabular}

Whatever the creep conditions, alloys 1 and 2 have similar rupture time and similar creep rate in the secondary stage. These alloys present better creep properties than XTM, i.e. lower creep rate in the secondary stage, higher creep rupture time and lower elongation at break. Creep rates in the secondary stage for alloys 3 and 4 are more than ten times higher than for alloys 1 and 2 and their rupture times are much shorter at $1050^{\circ} \mathrm{C} 17 \mathrm{MPa}$. Alloy 4 presents the worse creep behavior at $1050^{\circ} \mathrm{C}$. The creep properties of alloy 5 at $1050^{\circ} \mathrm{C} 22.2 \mathrm{MPa}$ and at $1050^{\circ} \mathrm{C} 17 \mathrm{MPa}$ are better than those of alloys 3 and 4 whereas Al content of alloy 5 is higher than the one of alloy 3 and equivalent to the one of alloy 4. Creep properties of Alloy 5 are roughly similar to those of alloys 1 and 2 but with a less abrupt ternary stage which ensure a more ductile fracture. The creep properties are much better than the reference Manaurite ${ }^{\circledR}$ XTM. These results show that Al rich alloys (up to $4.7 \mathrm{wt}$ \%) can exhibit better creep properties than the XTM which is without Al. Alloys 1, 2 and 5 are good candidates to replace the XTM used in cracking furnaces. 
Figure 14 presents the creep curves of alloys 1 to 5 at $1000^{\circ} \mathrm{C}$ under $31 \mathrm{MPa}$ from which rupture time, elongation at break and minimum creep rate in secondary stage were deduced (Table 6 ). As a reminder, NiAl phase is observed in alloys 2, 3, 4 and 5 after creep at $1000^{\circ} \mathrm{C}$.

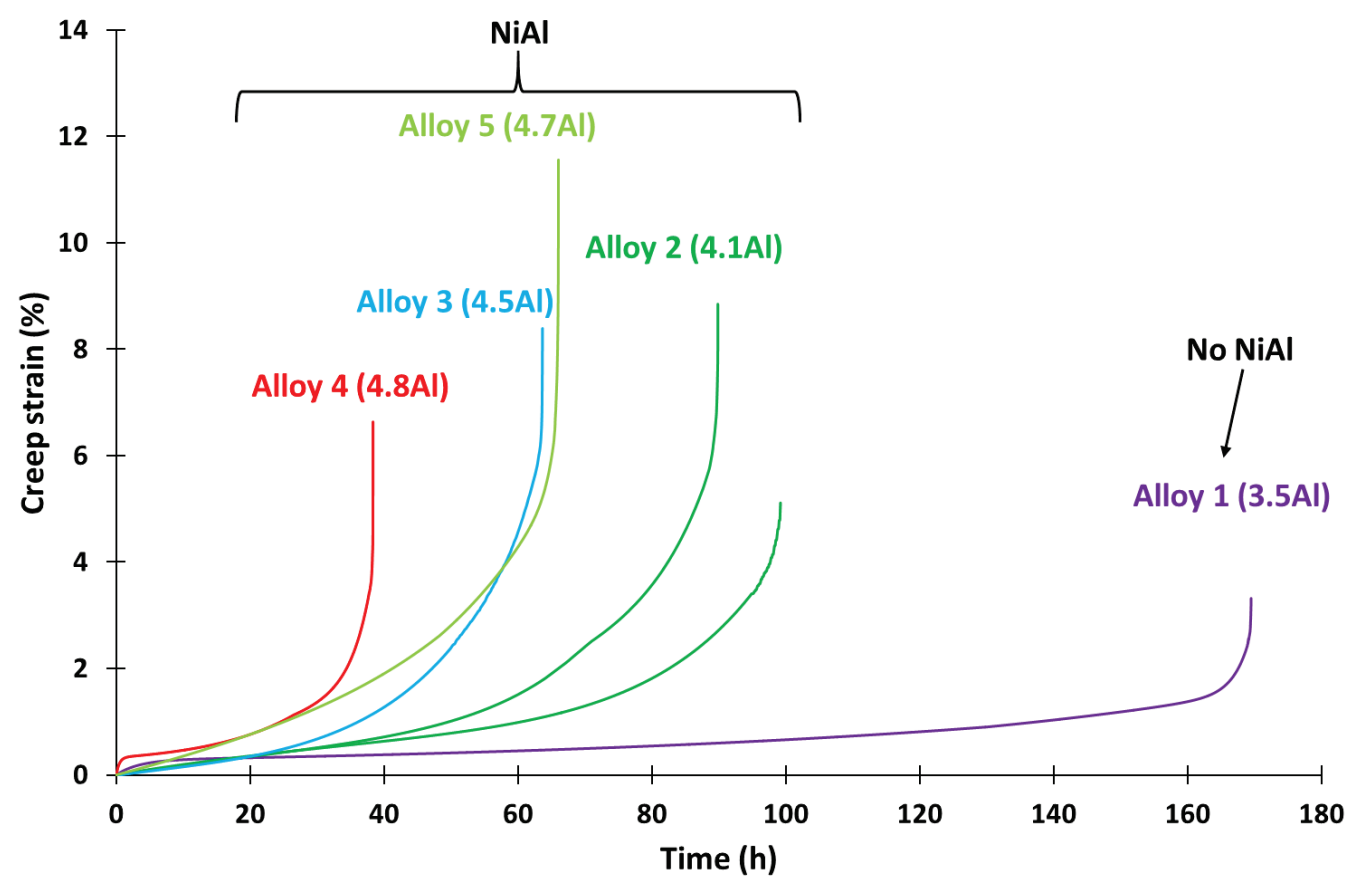

Figure 14: Creep curves at $1000^{\circ} \mathrm{C}$ under $31 \mathrm{MPa}$. Are also reported the Al-contents and pointed out the presence of NiAl.

Table 6: Creep rupture time and minimum creep rate at $1000^{\circ} \mathrm{C}$ under $31 \mathrm{MPa}$. Also given the NiAl presence (cross mark) in the crept specimen.

\begin{tabular}{cccc}
\hline & $\mathbf{t}_{\mathbf{r}}(\mathrm{h})$ & $\begin{array}{c}\dot{\boldsymbol{\varepsilon}}(\cdot \\
\left.\mathbf{1 0}^{-3} \mathbf{3} / \mathrm{h}\right)\end{array}$ & $\begin{array}{c}\mathrm{NiAl} \\
\text { presence }\end{array}$ \\
\hline Alloy 1 & 169.5 & 2.7 & - \\
\hline Alloy 2 & $89.8-$ & $13.4-16.1$ & $\mathrm{X}$ \\
& 99.2 & & \\
\hline Alloy 3 & 63.7 & 15.8 & $\mathrm{X}$ \\
\hline Alloy 4 & 38.3 & 12.1 & $\mathrm{X}$ \\
\hline Alloy 5 & 66.0 & 33.5 & $\mathrm{X}$ \\
\hline
\end{tabular}

As at $1050^{\circ} \mathrm{C}$, alloys 3 and 4 exhibit the worst creep properties with $\dot{\varepsilon}$ more than four times higher than values for alloy 1 at $1000^{\circ} \mathrm{C}$ under $31 \mathrm{MPa}$ and their rupture times are much shorter. Moreover, contrary to what was observed at higher temperature and lower stress, alloys 2 and 5 presents lower creep properties than alloy 1 with a higher creep rate in the secondary stage and lower creep rupture time. Alloy 1 presents a very abrupt ternary stage.

\section{Discussion: link between microstructure and creep properties}

A clear trend appears: the higher the mole fractions of $\mathrm{NiAl}$ and $\alpha^{\prime}$ phases the worse are the creep properties: creep rate in the secondary stage increases and the creep rupture time drops. Alloys with no NiAl and $\alpha^{\prime}$ phases exhibit good creep properties even if they contain Al. These results show that NiAl and $\alpha^{\prime}$ phase have a deleterious effect on creep resistance of the alloys. This deleterious effect of NiAl phase is confirmed by the behavior of alloys 2 and 5 . At $1050^{\circ} \mathrm{C}$, alloy 2 which does not contain any NiAl phase presents creep properties as good as alloy 1 . Likewise, alloy 5 exhibits good creep properties at $1050^{\circ} \mathrm{C}$, much better than the alloys 3 and 4 which contain $\mathrm{NiAl}$ phase. At $1000^{\circ} \mathrm{C}$ where some residual NiAl particles are observed, creep properties of alloys 2 and 5 decrease with respect to those of alloy 1. Alloy 1 shows the best creep resistance whatever the temperature. These good creep properties originate from the presence of the secondary carbides and the absence of NiAl phase. 


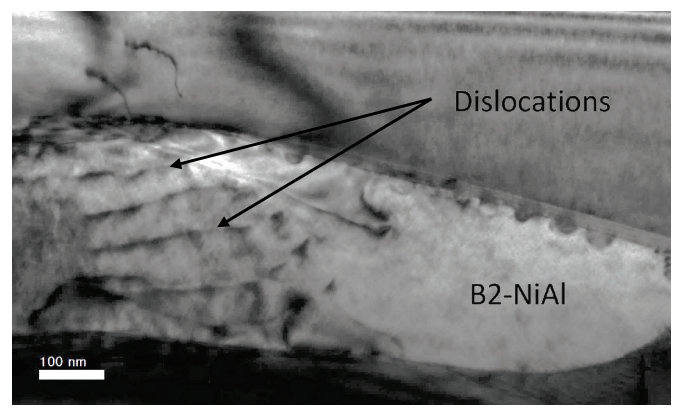

Figure 15: TEM image of dislocations in a NiAl plate in the alloy 4 after creep at $1050^{\circ} \mathrm{C}$.

The loss in strength and the increase in ductility of the $\mathrm{NiAl}$ and $\alpha^{\prime}$ phases can be pointed out in order to explain the deleterious character of these phases. Above $0.45 \mathrm{~T}_{\mathrm{m}}$ (melting temperature), NiAl shows a drop in strength [33,37] coincident with a sharp increase in ductility [33-36]. The drop in strength his even more pronounced above about $0.6 \mathrm{~T}_{\mathrm{m}}$ which corresponds to the service temperature of the materials presented in this paper [33]. Consequently, at service temperature, the NiAl phase does not remain an effective obstacle for dislocation motion $[12,13,16-19,38]$ and a loss of creep properties is observed. This agrees well with the TEM image presented in Figure 15 which reveals the presence of dislocation lines inside a NiAl precipitate characteristic of the ductile behavior of the NiAl phase. This assumption is consistent with the ductile behavior of the MCrAlY coatings attributed to the NiAl ductility [39-41]. Moreover, according to Texier et al. [39] who studied MCrAlY coating composed of $\gamma$-matrix, $\gamma^{\prime}$, $\mathrm{NiAl}$ and $\alpha^{\prime}, \alpha^{\prime}$ also contributes to the increase in ductility and the decrease in strength at high temperature. These ductile phases at service temperature are the limiting factor for creep resistance.

\section{Conclusions}

Several FeNiCrAl alloys with 3.5-4.8 wt. \% of Al were investigated in this paper. Their as cast microstructure consists in $\mathrm{M}_{7} \mathrm{C}_{3}$ and $\mathrm{MC}$ carbides after solidification. During ageing, secondary precipitation of carbides occurs and as a consequence improves the creep properties. Depending on their chemical composition, these alloys can contain $\mathrm{NiAl}$ and $\alpha$ ' phases at high temperatures as predicted by the thermodynamic simulations performed with the nickel database of Thermo-Calc ${ }^{\circledR}$ (TCNI8) and validated by the microstructural observations at $1000^{\circ} \mathrm{C}$ and $1050^{\circ} \mathrm{C}$. The results obtained clearly show the deleterious character of $\mathrm{NiAl}$ and $\alpha^{\prime}$ phases for the creep properties at service temperature $\left(1000^{\circ} \mathrm{C}\right.$ $1050^{\circ} \mathrm{C}$ ). High aluminum containing $\mathrm{FeNiCr}$ alloys with high creep properties are good candidates in order to replace the reference Manaurite ${ }^{\circledR}$ XTM alloy.

\section{Funding}

This work has been funded by the Agence Nationale de la Recherche (ANR), project IPERS, grant number LAB COM - 15 LCV4 0003.

\section{References}

[1] M.P. Brady, Y. Yamamoto, M.L. Santella, B.A. Pint, Effects of minor alloy additions and oxidation temperature on protective alumina scale formation in creep-resistant austenitic stainless steels, Scripta Materialia. 57 (2007) $1117-1120$.

[2] M.P. Brady, J. Magee, Y. Yamamoto, D. Helmick, L. Wang, Co-optimization of wrought alumina-forming austenitic stainless steel composition ranges for high-temperature creep and oxidation/corrosion resistance, Materials Science and Engineering: A. 590 (2014) 101-115. https://doi.org/10.1016/j.msea.2013.10.014.

[3] X. Xu, X. Zhang, G. Chen, Z. Lu, Improvement of high-temperature oxidation resistance and strength in aluminaforming austenitic stainless steels, Materials Letters. $65 \quad$ (2011) 3285-3288. https://doi.org/10.1016/j.matlet.2011.07.021.

[4] Y. Yamamoto, M.P. Brady, M.L. Santella, H. Bei, P.J. Maziasz, B.A. Pint, Overview of Strategies for HighTemperature Creep and Oxidation Resistance of Alumina-Forming Austenitic Stainless Steels, Metallurgical and Materials Transactions A. (2011). https://doi.org/10.1007/s11661-010-0295-2.

[5] M. P Brady, M. L Santella, Y. Yamamoto, C. Liu, High Nb, Ta, and Al creep- and oxidation-resistant austenitic stainless steel, US 7754144B2, n.d.

[6] M. P. Brady, B. A. Pint, C.-T. Liu, P. J. Maziasz, Y. Yamamoto, Z. P. Lu, Oxidation resistant high creep strength austenitic stainless steel, US 7744813B2, n.d.

[7] D. Jakobi, J. Weigandt, Advanced materials for radiant coils, AIChE Ethylene Producers Conference Proceedings. (2010) 474-489. 
[8] H. Asteman, W. Hartnagel, D. Jakobi, The Influence of Al Content on the High Temperature Oxidation Properties of State-of-the-Art Cast Ni-base Alloys, Oxid Met. 80 (2013) 3-12. https://doi.org/10.1007/s11085-013-9381-3.

[9] F. Pons, J. Thuillier, Nickel- and chromium-base alloys possessing very-high resistance to carburization at veryhigh temperature, 4.248.629, n.d. http://www.google.com/patents/US4248629 (accessed November 24, 2017).

[10] Y. Yamamoto, G. Muralidharan, M.P. Brady, Alumina forming iron base superalloy, US8815146B2, 2014. https://patents.google.com/patent/US8815146B2/en (accessed August 12, 2019).

[11] D.V.V. Satyanarayana, G. Malakondaiah, D.S. Sarma, Steady state creep behaviour of NiAl hardened austenitic steel, Materials Science and Engineering: A. 323 (2002) 119-128. https://doi.org/10.1016/S0921-5093(01)013429.

[12] D.V.V. Satyanarayana, G. Malakondaiah, D.S. Sarma, Characterization of the age-hardening behavior of a precipitation-hardenable austenitic steel, Materials Characterization. 47 (2001) 61-65. https://doi.org/10.1016/S1044-5803(01)00153-X.

[13] H. Bei, Y. Yamamoto, M.P. Brady, M.L. Santella, Aging effects on the mechanical properties of alumina-forming austenitic stainless steels, Materials Science and Engineering: A. 527 (2010) 2079-2086. https://doi.org/10.1016/j.msea.2009.11.052.

[14] B. Hu, G. Trotter, I. Baker, M.K. Miller, L. Yao, S. Chen, Z. Cai, The Effects of Cold Work on the Microstructure and Mechanical Properties of Intermetallic Strengthened Alumina-Forming Austenitic Stainless Steels, Metall and Mat Trans A. 46 (2015) 3773-3785. https://doi.org/10.1007/s11661-015-2981-6.

[15] G. Trotter, B. Hu, A.Y. Sun, R. Harder, M.K. Miller, L. Yao, I. Baker, Precipitation kinetics during aging of an alumina-forming austenitic stainless steel, Materials Science and Engineering: A. 667 (2016) 147-155. https://doi.org/10.1016/j.msea.2016.04.081.

[16] G. Trotter, I. Baker, Orientation relationships of Laves phase and NiAl particles in an AFA stainless steel, Philosophical Magazine. 95 (2015) 4078-4094. https://doi.org/10.1080/14786435.2015.1111529.

[17] B. Zhao, J. Fan, Y. Liu, L. Zhao, X. Dong, F. Sun, L. Zhang, Formation of L12-ordered precipitation in an aluminaforming austenitic stainless steel via $\mathrm{Cu}$ addition and its contribution to creep/rupture resistance, Scripta Materialia. 109 (2015) 64-67. https://doi.org/10.1016/j.scriptamat.2015.07.019.

[18] D.Q. Zhou, W.X. Zhao, H.H. Mao, Y.X. Hu, X.Q. Xu, X.Y. Sun, Z.P. Lu, Precipitate characteristics and their effects on the high-temperature creep resistance of alumina-forming austenitic stainless steels, Materials Science and Engineering: A. 622 (2015) 91-100. https://doi.org/10.1016/j.msea.2014.11.013.

[19] D.Q. Zhou, X.Q. Xu, H.H. Mao, Y.F. Yan, T.G. Nieh, Z.P. Lu, Plastic flow behaviour in an alumina-forming austenitic stainless steel at elevated temperatures, Materials Science and Engineering: A. 594 (2014) 246-252. https://doi.org/10.1016/j.msea.2013.11.021.

[20] Y. Yamamoto, M. Takeyama, Z.P. Lu, C.T. Liu, N.D. Evans, P.J. Maziasz, M.P. Brady, Alloying effects on creep and oxidation resistance of austenitic stainless steel alloys employing intermetallic precipitates, Intermetallics. 16 (2008) 453-462. https://doi.org/10.1016/j.intermet.2007.12.005.

[21] Schmidt + Clemens, Centralloy 60 HT R MATERIAL DATA SHEET, (2015).

[22] Brochures Manoir Petrochem, (n.d.). http://www.manoir-industries.com/site/fr/ref/Manoir-PetrochemBrochures_75-72.html (accessed January 31, 2018).

[23] G.D. de Almeida Soares, L.H. de Almeida, T.L. da Silveira, I. Le May, Niobium additions in HP heat-resistant cast stainless steels, Materials Characterization. 29 (1992) 387-396. https://doi.org/10.1016/1044-5803(92)90045$\mathrm{J}$.

[24] F. Tancret, J. Laigo, F. Christien, R.L. Gall, J. Furtado, Phase transformations in Fe-Ni-Cr heat-resistant alloys for reformer tube applications, Materials Science and Technology. 34 (2018) 1333-1343. https://doi.org/10.1080/02670836.2018.1449177.

[25] B. Piekarski, J. Kubicki, Creep-resistant austenitic cast steel, Archives of Foundry Engineering. Vol. 8, iss. 2 (2008) 115-120.

[26] M. Wang, D. Flahaut, Z. Zhang, I.P. Jones, Y.L. Chiu, Primary carbide transformation in a high performance micro-alloy at $1000^{\circ} \mathrm{C}$, Journal of Alloys and Compounds. 781 (2019) 751-760. https://doi.org/10.1016/j.jallcom.2018.12.095.

[27] R. Voicu, J. Lacaze, E. Andrieu, D. Poquillon, J. Furtado, Creep and tensile behaviour of austenitic $\mathrm{Fe}-\mathrm{Cr}-\mathrm{Ni}$ stainless steels, Materials Science and Engineering: A. 510-511 (2009) 185-189. https://doi.org/10.1016/j.msea.2008.04.098.

[28] M. Roussel, X. Sauvage, M. Perez, D. Magné, A. Hauet, A. Steckmeyer, M. Vermont, T. Chaise, M. Couvrat, Influence of solidification induced composition gradients on carbide precipitation in FeNiCr heat resistant steels, Materialia. 4 (2018) 331-339. https://doi.org/10.1016/j.mtla.2018.10.010.

[29] Manaurite ${ }^{\circledR}$ XAl4, Manoir Industries. (n.d.). https://www.manoir-industries.com/documentation-termsconditions/leaflets/2018manaurite-xal4_pdf_planche/ (accessed February 21, 2019).

[30] Thermo-Calc Software, TCS Ni-Based Superalloys Database Version 8.1, (n.d.). 
[31] Thermo-Calc Software, TCS Fe-Based Steels Database Version 8.1, (n.d.).

[32] Nickel-based superalloys - Thermo-Calc Software, (n.d.). https://www.thermocalc.com/solutions/bymaterial/nickel-based-alloys/ (accessed January 28, 2019).

[33] I. Baker, A review of the mechanical properties of B2 compounds, Materials Science and Engineering: A. 192 193 (1995) 1-13. https://doi.org/10.1016/0921-5093(94)03200-9.

[34] A. Ball, R.E. Smallman, The deformation properties and electron microscopy studies of the intermetallic compound NiAl, Acta Metallurgica. 14 (1966) 1349-1355. https://doi.org/10.1016/0001-6160(66)90251-3.

[35] K.H. Hahn, K. Vedula, Room temperature tensile ductility in polycrystalline B2 NiAl, Scripta Metallurgica. 23 (1989) 7-12. https://doi.org/10.1016/0036-9748(89)90083-5.

[36] R. Darolia, NiAl alloys for high-temperature structural applications, JOM. 43 (1991) 44-49. https://doi.org/10.1007/BF03220163.

[37] Y. Liao, I. Baker, Evolution of the microstructure and mechanical properties of eutectic Fe30Ni20Mn35A115, Journal of Materials Science. 46 (2011) 2009-2017. https://doi.org/10.1007/s10853-010-5197-6.

[38] Y. Yamamoto, G. Muralidharan, M.P. Brady, Alumina forming iron base superalloy, (2014). http://www.google.com/patents/US8815146.

[39] D. Texier, D. Monceau, F. Crabos, E. Andrieu, Tensile properties of a non-line-of-sight processed $\beta-\gamma-\gamma$ ' MCrAlY coating at high temperature, Surface and Coatings Technology. 326, Part A (2017) 28-36. https://doi.org/10.1016/j.surfcoat.2017.07.026.

[40] D. Pan, M.W. Chen, P.K. Wright, K.J. Hemker, Evolution of a diffusion aluminide bond coat for thermal barrier coatings during thermal cycling, Acta Materialia. 51 (2003) 2205-2217. https://doi.org/10.1016/S13596454(03)00014-4.

[41] R. Subramanian, Y. Mori, S. Yamagishi, M. Okazaki, Thermo-mechanical Fatigue Failure of Thermal Barrier Coated Superalloy Specimen, Metallurgical and Materials Transactions A. 46 (2015) 3999-4012. https://doi.org/10.1007/s11661-015-2996-z. 